\title{
Peculiarities of the Relationship Between Cultural Policy, Communication and Cultural Worldview
}

\author{
Oksana G. Basalaeva* \\ Kemerovo State University of Culture and Arts \\ Kemerovo, Russian Federation
}

Received 23.03.2021, received in revised form 06.04.2021, accepted 21.05.2021

\begin{abstract}
The article is focused on the issue of determining the key ideological prerequisites and means of forming social consciousness, which cultural policy is based on. The article argues that one of the means that forms the worldview of a society and individuals' activity in terms of understanding cultural policy is cultural worldview, which acts as a «mediator» and a channel of communication between the state, the scientific community and public consciousness. It has been analyzed that the most important task on the way to achieving the main goals of the state cultural policy is not only broad information about the essence of cultural policy but understanding this essence. As a result, a tendency: «cultural policy - intercultural communication, as an object of cultural policy - cultural worldview, as a means of intercultural communication» has been revealed at the present stage of socio-cultural development. Moreover, it has been substantiated that the patterns of intercultural communication reflect the relations between cultural systems, indicate their internal connections and relationships (the structure of cultural reality) and, thereby, form cultural worldview.
\end{abstract}

Keywords: communication, intercultural communication, socio-cultural communication, cultural policy, cultural worldview, cultural system.

Research areas: culturology, philosophy.

Citation: Basalaeva, O.G. (2021). Peculiarities of the relationship between cultural policy, communication and cultural worldview. J. Sib. Fed. Univ. Humanit. Soc. Sci., 14(6), 767-773. DOI: 10.17516/1997$1370-0758$

\footnotetext{
(C) Siberian Federal University. All rights reserved

* Corresponding author E-mail address: oksana basalaeva@mail.ru ORCID: 0000-0001-6053-0001
} 


\title{
Особенности взаимосвязи культурной политики, коммуникации и культурной картины мира
}

\author{
О.Г. Басалаева \\ Кемеровский государственный институт культуры \\ Российская Федерация, Кемерово
}

\begin{abstract}
Аннотация. Предметом рассмотрения в данной статье является проблема определения ключевых мировоззренческих предпосылок и средств формирования социального сознания, на основе которых фундируется культурная политика. В статье аргументировано, что одно из средств, которое формирует мировоззрение общества и активность индивидов в отношении понимания культурной политики, это культурная картина мира, служащая «посредником», каналом коммуникации между государством, научным сообществом и общественным сознанием. Проанализировано, что важнейшей задачей, стоящей на пути к достижению основных целей государственной культурной политики, считается не только широкое информирование о сущности культурной политики, но и понимание этой сущности. В результате выявлена тенденция в социокультурном развитии на современном этапе: «культурная политика - межкультурная коммуникация как объект культурной политики - культурная картина мира как средство межкультурной коммуникации». Более того, обосновано, что закономерности межкультурной коммуникации отражают связи между культурными системами, указывают на их внутренние связи и отношения (структуру культурной реальности) и тем самым формируют культурную картину мира.
\end{abstract}

Ключевые слова: коммуникация, межкультурная коммуникация, социокультурная коммуникация, культурная политика, культурная картина мира, культурная система.

Научные специальности: 24.00 .00 - культурология, 09.00 .00 - философские науки.

\section{Введение}

\section{в проблему исследования}

Размышления о коммуникации, культурной политике и культурной картине мира следует начинать с того, что, в принципе, речь идет не только о «качественно близких» терминах, но и взаимозависимых пластах идей, лежащих в их основании.

Обзор концептуальных понятий культурной политики показывает, что спектр определений культурной политики чрезвычайно широк (Koptseva, Luzan, 2012: 8-29). В современных условиях понятие «культурная политика» получило интерпретацию, связанную государственной идеологией (Koptseva, Luzan, 2012: 8-29). Кроме того, культурная политика связана с национальной идеологией. Основным условием формирования национальной идеологии является национальная идея. Достаточно детально национальная идея рассмотрена О. Карлова (Karlova, 2019). Н. П. Копцева и В.С. Лузан делают следующие выводы. С одной стороны, государство как репрезентант социума и культуры задает, исходя из государственных интересов, идеалы, нормы, ценности культурной жизнедеятельности. Данная форма государственной активности институциализируется в системе государственной культурной политики. С другой - продукты процесса культурогенеза объективно утверждаются в обществе (но не обязательно в государстве) как следствие объективных тенденций самого культурного процесса через исторически сложившиеся идеалы, нормы, 
традиции и т. д. Причем данные взаимоотношения культурной политики и культурной реальности конкретно-исторически всегда противоречивы (Koptseva, Luzan, 2012: 8-29).

В «Основах государственной культурной политики» к объектам культурной политики отнесены системы межличностной и общественной коммуникации (Ukaz ..., 2014).

В течение длительного времени вокруг центрального понятия «коммуникация» ведутся серьезные дискуссии. В зависимости от его трактовки и смыслового наполнения коммуникация становится объектом исследования разных областей научного знания, категорией, вокруг которой выстраиваются концепции и формируются подходы к исследованию мира материальных объектов и символов, ценностей, искусственных порядков и человеческих отношений. Наиболее полный обзор научных исследований феномена «коммуникация» сделан в публикации Н. Копцевой, Ма Лии, В. Кирко (Koptseva, Liia, Kirko, 2015). В культурологии коммуникация рассматривается с разных позиций как важнейший аспект культурных процессов и систем (Basalaeva, Balabanov, 2015: 129). Особым видом коммуникации является межкультурная коммуникация.

Коммуникация, развивающаяся в разных направлениях, как на фундаментальном, так и на прикладном уровнях в полной мере готова отвечать на вызовы времени. Соответственно, применительно к культурной политике культурологический подход к коммуникации также претерпевает значительные трансформации, что связано с переосмыслением базовых категорий в контексте социальных и культурных изменений современного мира.

\section{Концептологические основания} и методология исследования

Анализ взаимосвязи коммуникации, культурной политики и культурной картины мира базируется на синтезе новейших концептуальных подходов к методологии междисципли- нарности социально-гуманитарных наук (Demetradze, 2013).

Авторское исследование данной проблемы опирается на два междисциплинарных подхода. Подход, заявленный «понимающей социологией», представители которой считают, что основным результатом коммуникации служит понимание человеком другого человека, т. е. взаимопонимание двух субъектов общения. Суть подхода заключается в том, что коммуникация считается не просто процессом передачи/приема информации, это создание некой общности, некой степени взаимопонимания между участниками. Это деятельностный подход, определяющий коммуникацию как совместную деятельность участников коммуникации, в ходе которой вырабатывается общий взгляд на вещи и действия с ними, т. е. общая картина мира. Здесь объединяющим началом являются человек и его деятельность. Для деятельностного подхода характерны процессуальность, континуальность, контекстуальность. Последний подход ближе к реальной жизни и более гуманистичен.

\section{Постановка проблемы}

В «Основах государственной культурной политики» в компактной форме заложен целый ряд важнейших идей, ключевой из которых выступает идея о том, что культура не должна сводиться к сфере услуг, что культура - это, прежде всего, социальный механизм передачи коллективного знания и системы ценностей. В документе четко обозначено, что именно единение науки, образования и искусства закладывает основу для понимания общественной миссии культуры как инструмента передачи новым поколениям свода моральных, этических и эстетических ценностей, составляющих ядро национальной самобытности (Ukaz ..., 2014).

Как верно замечено В. Аристарховым, это документ политический, он основывается на определенных мировоззренческих предпосылках, но формат официального текста не предполагает детального изложения таких предпосылок, они лишь обозна- 
чаются или подразумеваются (Aristarkhov, 2019).

Поэтому возникает проблема определения ключевых мировоззренческих предпосылок и средств, которые формирует мировоззрение общества. По нашему мнению, одним из средств, которое формирует мировоззрение общества и активность индивидов в отношении понимания смысла и реализации культурной политики, является культурная картина мира, служащая «посредником», каналом коммуникации между государством, научным сообществом и общественным сознанием. Проблема усложняется наличием многообразия подходов к дефинициям таких понятий, как «культурная политика», «коммуникация», «культурная картина мира».

Вышесказанное свидетельствует о необходимости уточнения представлений о связи между культурной политикой, коммуникацией, и культурной картиной мира, которая, по нашему мнению, осуществляется через трансляцию ценностей и методов, а также посредством внутрикоммуникационных отношений в обществе.

\section{Обсуждение}

Государством обозначены основные цели и ключевые задачи в области культурной политики по различным направлениям. Но, по нашему мнению, важнейшая задача, стоящая на пути к поставленным целям, не только широкое информирование о сущности культурной политики, но и понимание этой сущности. Решению данной задачи, с одной стороны, служит расширение каналов коммуникации между государством, культурой (включая науку и образование как часть культуры) и мультикультурным обществом (симбиоз традиций и обычаев различных народов, национальных культур, религий), а с другой - готовность мультикультурного общества принять и усвоить передовые идеи.

Все это позволяет выявить тенденцию в социокультурном развитии на современном этапе: «культурная политика - межкультурная коммуникация как объект культурной политики - культурная картина мира как средство межкультурной коммуникации».

Культурная картина мира - это продукт философско-культурологических изысканий ряда ученых и мыслителей, формирующих знание о культуре во всем его многообразии - культурной реальности (Basalaeva, 2016). Одной из составляющих культурной реальности выступает наличие фундаментальных теоретических законов в культурологическом знании. К ним относятся, прежде всего, закономерность межкультурной коммуникации.

Основным звеном в обозначенной выше тенденции, по нашему мнению, является межкультурная коммуникация, поскольку современный мир превращается в безграничную сферу и ассимилируется в глобальную культуру. Межкультурные коммуникации могут позволить преодолеть межнациональные барьеры во всем мире, а также культурные барьеры, которые возникают между субкультурами в пределах одной страны. Здесь основная задача - определить эффективные способы передачи информации культурно различным группам таким образом, чтобы избежать культурной поляризации (Medin, Bang, 2014: 13625).

Отсутствие общепризнанной теории коммуникации восполняется набором авторских концепций. Достаточно адекватной и широко распространенной считается интерпретация процесса коммуникации в работах Э. Холла (Hall, 1968, 1989, 1990), ведущего исследователя в области межкультурной коммуникации. Согласно его мнению, у каждого типа культуры существуют определенные модели коммуникации, связанные, прежде всего, с осознанием культурной ценности. Причем культурные коммуникации более глубокие и сложные, чем устные или письменные сообщения. Ученый разделил культуру на два идентифицируемых класса для четкого представления картины мира, которую изображают культуры с высоким и низким контекстом.

Э. Холл к высококонтекстуальным культурам отнес Россию. Благодаря накопленному опыту и традициям межличностные отношения в таких культурах отлича- 
ются наличием множества скрытых правил и требований, длительностью, однородностью, стабильностью и прочностью.

Низкоконтекстуальные культуры характеризуются меньшим объемом информации и более свободной сетью связей в социальном окружении. Причем приоритет в коммуникациях отдается «открытому» смыслу сказанных слов или письменным договоренностям, а не контексту разговора или ситуации, в которой происходит общение (Hall, 1989).

В данной классификации степень информированности (контекст и количество информации) служит одним из параметров, по которым можно определить характер и результаты процесса коммуникации.

Концепция Э. Холла дала импульс к изучению особенностей коммуникации среди зарубежных и отечественных исследователей. Г. С. Триандис, основываясь на анализе, проведенном Г.Х. Хофстеде (Hofstede, 1980, Hofstede, Hofstede, 1991), обосновал специфику кросс-культурных коммуникаций, опираясь на идеи индивидуализма и коллективизма. Одна из главных особенностей коммуникации в индивидуалистических и коллективистических культурах - существенная разница в стиле общения со «своими» и «чужими». Известно, что «освоение мира происходит в соответствии с определением бинарных архетипов в сознании человека, которые предполагают удобную схему различения и противопоставления «своего» и «чужого», способствующую установлению границ пространства человеческого мира, культуры» (Astakhov, Rtishcheva, 2017: 26).

Проанализировав результаты исследований, Триандис определил существенные отличия в поведении коллективиста и индивидуалиста в различных ситуациях. Например, для коммуникации в коллективистических культурах характерно сложное общение с представителями «чужих» групп, для коммуникации в индивидуалистических культурах свойственна эмоциональная обособленность от группы «своих», за исключением нуклеарной семьи (Triandis, 1994).
Интеграция коллективного и индивидуального осмысления, встраиваемая посредством упорядочения в определенных когнитивных моделях в систему ценностносмысловых оснований культурной политики, позволила Триандису оформить концепцию и представить ее обществу.

Известный отечественный культуролог А.Я. Флиер предлагает иную типологию. Одним из оснований автор считает уровень протекания коммуникации:

- уровень обыденной культуры;

- уровень специализированных областей социокультурной практики;

- уровень трансляции культурного опыта от специализированного уровня к обыденному и т. п. (Flier, 2015)

Новый профиль культурной политики формируется ее коммуникативной моделью, основанной на взаимопонимании между участниками социокультурной деятельности. Достижение социального эффекта от проводимых модернизационных преобразований невозможно без придания инновационного характера развитию научно-образовательной сферы. Например, Е. Тарева, Б. Тарев доказали ведущую роль кейс-метода в формировании межкультурной коммуникативной компетенции обучающихся, позволяющей преодолеть конфликт диалога культур (Tareva, Tarev, 2018). По мнению Д. Л. Медина и М. Банга, научная коммуникация в более широком смысле отражается в естественнонаучном образовании, как формальном, так и неформальном (Medin, Bang, 2014: 13621).

\section{Заключение}

Подводя итоги, отметим, что в современных социокультурных условиях участвуют системы, не только разнообразные по уровню экономического развития, но и обладающие различной культурной спецификой, ценностным содержанием, системами представлений, картинами мира.

Такой коммуникативный подход является востребованным и результативным в ситуации множественности культур и социокультурного разнообразия, открытости к интеграции в глобализирующемся мире. 
Эффективная коммуникация между культурами - это инструмент успеха в политической практике.

Таким образом, выделение такой фундаментальной закономерности предметной области культурологии, т. е. культурной реальности как закономерности межкультурной коммуникации, характеризует связи между культурными системами, указывает на внутренние связи и отношения (структуру культурной реальности) и тем самым формирует культурную картину мира.

\section{Список литературы}

Аристархов, В.В. (2019). Основы «Основ». О смыслах государственной культурной политики // Культурологический журнал, 2(36), режим доступа: http://cr-journal.ru/rus/journals/469.html\&j_id=39

Астахов, О.Ю., Ртищева, О.В. (2017). Субъектное содержание коммуникационных процессов в условиях современной культуры // Международный журнал исследований культуры, 2 (27), 20-26, eISSN2079-1100.

Басалаева, О.Г., Балабанов, П.И. (2015) Особенности процессов коммуникации в науке, культуре и обществе // Вестник Кемеровского государственного университета культуры и искусств, 32(3), $127-132$.

Деметрадзе M.P. (2013). Социокультурная основа междисциплинарной методологии социально-гуманитарных наук // Социодинамика, 12, 17-40. DOI: 10.7256/2306-0158.2013.12.1072, режим доступа: https://nbpublish.com/library_read_article.php?id=10727,

Копцева, Н.П., Лузан, В.С. (2012). Государственная культурная политика в Сибирском федеральном округе. Концепции, проблемы, исследования. Красноярск, Издательство Сибирского федерального университета, $160 \mathrm{c}$.

Указ Президента РФ от 24.12.2014 № 808 «Об утверждении Основ государственной культурной политики» (2014). Режим доступа:: https://www.consultant.ru/document/cons_doc_LAW_172706 (дата обращения 25.02.2019).

Флиер, А.Я. (2015). Человек и культура: параметры сопряженности // Kультура культурьь, (2), режим доступа: http://cult-cult.ru/human-and-culture-factors-of-congruence/

\section{References}

Aristarkhov, V.V. (2019) Osnovih «Osnov». O smihslakh gosudarstvennoyj kuljturnoyj politiki [Basics of «Basics». On the meaning of the state cultural policy]. In Kuljturologicheskiyj zhurnal [Journal of cultural research], 2(36), available at: http://cr-journal.ru/rus/journals/469.html\&j_id=39

Astakhov, O. Yu., Rtishcheva, O.V. (2017). Subjhektnoe soderzhanie kommunikacionnihkh processov v usloviyakh sovremennoyj kuljturih [Subject Content of Communication Processes in Modern Culture]. In Mezhdunarodnihyj zhurnal issledovaniyj kuljturih [International Journal of Cultural Research], 2 (27), 20-26, eISSN2079-1100.

Basalaeva, O.G. (2016). Features of cultural reality in cultural world-view. In J. Sib. Fed. Univ. Humanit. soc. sci., 9(2), 342-349.

Basalaeva, O.G., Balabanov, P.I. (2015). Osobennosti processov kommunikacii v nauke, kuljture i obthestve [Features processes of communication in science, culture and society]. In Vestnik Kemerovskogo gosudarstvennogo universiteta kuljturih i iskusstv [Bulletin of Kemerovo State University of Culture and Arts], 32(3), 127-132.

Demetradze, M.R. (2013). Sociokuljturnaya osnova mezhdisciplinarnoyj metodologii socialjnogumanitarnihkh nauk [Socio-cultural basis of the interdisciplinary methodology of the social sciences and humanities]. In Sociodinamika [Sociodynamics], (12), 17-40. DOI: 10.7256/2306-0158.2013.12.1072, available at: https://nbpublish.com/library_read_article.php?id=10727

Flier, A. Ya. (2015). Chelovek i kul'tura: parametry sopryazhennosti [Man and culture: the parameters of the contingency]. In Kul'tura kul'tury [Culture of culture], (2), available at: http://cult-cult.ru/human-andculture-factors-of-congruence/ 
Hall, E.T. (1990). Understanding Cultural Differences, Germans, French and Americans. Yarmouth: Intercultural Press.

Hall, E.T. (1968). The Silent Language. Fawcett.

Hall, E.T. (1989). Beyond Culture. Anchor Books.

Hofstede, G.H. (1980) Culture's Consequences: International Differences in Work-Related Values. London and Beverly Hils, 475 p.

Hofstede, G.H., Hofstede, G.J. (1991). Allemaal Andersdenkenden: Omgaan met Cultuurverschillen. Amsterdam, Contact, 432 p.

Karlova, O.A. (2019). National idea in Russia: cultural and historical genesis and factors of actualization. In J. Sib. Fed. Univ. Humanit. soc. sci., 12(6), 996-1016. DOI: 10.17516/1997-1370-0437.

Koptseva, N.P., Liia, Ma, Kirko, V.I. (2015). The Concept of «Communication» in Contemporary Research. In J. Sib. Fed. Univ. Humanit. soc. sci., (8), 1560-1568.

Koptseva, N.P., Luzan, V.S. (2012). Gosudarstvennaia kul'turnaia politika v Sibirskom federal'nom okruge: kontseptsii, problemy, issledovaniia [State Cultural Policy in the Siberian Federal District: Concepts, I.s, Research]. Krasnoyarsk, Izdateljstvo Sibirskogo Federaljnogo Universiteta, 160 p.

Medin, D.L., Bang, M. (2014) The cultural side of science communication. In Proceedings of the National Academy of Sciences, 111(4), 13621-13626. DOI: 10.1073/pnas.1317510111.

Tareva, E.G., Tarev, B.V. (2018). Cases on intercultural communication: new approach to design. In J. Sib. Fed. Univ. Humanit. soc. sci., 11(10), 1699-1710. DOI: 10.17516/1997-1370-0329.

Triandis, H.C. (1994). Culture and social behavior. New York, McGraw-Hill, 320 p.

Ukaz Prezidenta RF ot 24.12.2014 № 808 «Ob utverzhdenii Osnov gosudarstvennoyj kuljturnoyj politiki» (2014). Available at: https://www.consultant.ru/document/cons_doc_LAW_172706 (accessed 25 February 2019). 